\title{
Fracturing Gels as Analogs to Understand Fracture Behavior in Shale Gas Reservoirs
}

\author{
Zheng $\mathrm{Li}^{1} \cdot$ Jingyi Wang ${ }^{1} \cdot \operatorname{lan} \mathrm{D}$. Gates $^{1}$ (D)
}

Received: 23 October 2019 / Accepted: 19 May 2020 / Published online: 25 May 2020

(c) The Author(s) 2020

\begin{abstract}
Hydraulic fracturing is widely used in the exploitation of unconventional reservoirs, such as shale gas and tight gas. However, a full understanding of the activation of natural fractures, prediction of fracture growth, distribution of proppant, and network fracture system effectiveness remain unresolved. The onset of fracturing in the media requires energy and this is due to the buildup of pressure within the rock due to continuous injection of fluid. In other words, when the energy associated with the injection fluid reaches the fracture strength of the rock, the fracture initiates and propagates into the formation. Here, we use gelatin in hydraulic fracturing laboratory tests and compare the results to a modified radial hydraulic fracturing theory. The mechanics of the gelatin, procedures to make a testing gelatin block, and procedures to conduct the test are described. The results show that the fracture evolving behaviours from experiments are well matched by the theory. The results are then scaled up to understand fracture growth behaviour in a tight rock reservoir.
\end{abstract}

Keywords Hydraulic fracturing $\cdot$ Unconventional oil and gas $\cdot$ Tight gas $\cdot$ Shale gas $\cdot$ Fracture model $\cdot$ Experimental fracturing · Gelatin

\section{Introduction}

Hydraulic fracturing is widely used to produce petroleum from unconventional reservoirs, such as shale and tight gas reservoirs (Rahm 2011; Rutqvist et al. 2013; Arthur et al. 2009; Cipolla et al. 2010; Olson 2008; Warpinski 1991,1990; Rodgerson 2000; Gregory et al. 2011). Generally, these kind of reservoirs have extremely low permeabilities and are impossible to produce economically without effective stimulation such as hydraulic fracturing. There are many reports in the literature on hydraulic fracturing experiments in the laboratory (Zoback et al. 1977; Blanton 1982; Teufel and Clark 1981; Jaworski et al. 1981; Matsunaga et al. 1993; Potluri et al. 2005; Lockner 1993) and in general, these experiments are used to determine the nature of rock fracturing, propagation of fractures, and geomechanical properties of the rock. One of the key concerns facing hydraulic fracturing operations is the ability to model these

Ian D. Gates

ian.gates@ucalgary.ca

1 Department of Chemical and Petroleum Engineering, University of Calgary, Calgary, AB, Canada systems and validate these models using experiments or field observations on the route to build predictive models.

In typical practice, computer-based models are calibrated to field operations and these history-matched models are then used to predict fracturing operations at other stages or other wells. However, it is well-known that most models are not predictive given the uncertainties of the geological and geomechanical properties, the assumptions taken to construct the model, and approximations invoked using the numerical method. Here, we propose the use of simple physical model experiments using gelatin to physically simulate hydraulic fracturing with scaling to examine hydraulic fracturing in real reservoirs. Gelatin is a product obtained from partial hydrolysis of collagen derived from skin, white connective tissue, and bones of animals. The principal raw materials used in gelatin production are cattle bones, cattle hides, and pork skins. Several alternative sources include poultry and fish. Extraneous substances, such as minerals in the case of bone, fats and albuminoid from skin, are removed by chemical and physical treatment to obtain purified collagen. These pretreated materials are then hydrolyzed to gelatin which is soluble in hot water. Gelatin is a vitreous, brittle solid that contains $8-13 \%$ moisture and has a density between 1.2 and $1.4 \mathrm{~g} / \mathrm{cc}$. When gelatin granules are soaked 
in cold water they hydrate into discrete, swollen particles. On being warmed, these swollen particles dissolve to form a solution. The behavior of gelatin solutions is influenced by temperature, $\mathrm{pH}$, ash content, method of manufacture, thermal history, and concentration. Gelatin stored in air-tight containers at room temperature remains unchanged for long periods of time.

Due to its suitable properties such as transparency and elasticity, gelatin has been widely used for many mechanical purposes, for example, ballistic testing and tissue engineering (Kwon and Subhash 2010; Salisbury and Cronin 2009; Kang et al. 1999; Lee and Mooney 2001). In this paper, we use gelatin as a physical model to study hydraulic fracturing, compare results to a simple analytical theory, and apply the results to examine fracturing in tight rock reservoirs using scaling theory.

\section{Materials and Methods}

\subsection{Gelatin Preparation}

Knox gelatin powder is used to make our mechanical property test and hydraulic fracturing test, because it is a wellknown good material in ballistic testing. In preparation of hydraulic fracturing test, gelatin powder of $285 \mathrm{~g}$ is poured into a pan and dissolved in water of $3300 \mathrm{~g}$ and is stirred for about $3 \mathrm{~min}$. It may still have some suspended particles which are not easily dissolved at room temperature. To get clear gelatin for experiments, the turbid liquid must be heated to more than $60{ }^{\circ} \mathrm{C}$ until it is clear. Then the solution is then poured into the hydraulic fracturing container (dimensions $150 \mathrm{~mm}$ wide by $150 \mathrm{~mm}$ long by $155 \mathrm{~mm}$ high). After cooling and solidification the gelatin is ready for further hydraulic fracturing test. In tests for mechanical properties, procedures to prepare the gelatin block is the same as in hydraulic fracturing test except that a different container (dimensions $74 \mathrm{~mm}$ wide by $78 \mathrm{~mm}$ long by $70 \mathrm{~mm}$ high). Figure 1 shows the gelatin made for mechanical properties test in a container and on a flat surface.

\subsection{Mechanical Properties of Gelatin}

The mechanical properties of gelatin versus weight percentage of gel powder, temperature, and solidification time were determined using a Brookfield Texture Analyzer (Model CT3, Brookfield). The compression test was conducted with three cycles, where a maximum strain of $10 \%$ is used. The height of the gelatin blocks used in the experiments is $70 \mathrm{~mm}$ and the deformation rate used in the Texture Analyzer is $0.1 \mathrm{~mm} / \mathrm{s}$ (with hold time equal to $3 \mathrm{~s}$ ). Within $10 \%$ deformation (which occurs over the first $60 \mathrm{~s}$ of the test), the stress-strain relationship is linear and thus, within this deformation range, the gelatin acts as an elastic material. For each test, the Young's modulus and Possion's ratio are determined from the deformation data.

Figure 2 displays the Young's modulus versus temperature (at $8 \mathrm{wt} . \%$ gelatin and $18 \mathrm{~h}$ solidification time), solidification time (at $8 \mathrm{wt} . \%$ gelatin and $23^{\circ} \mathrm{C}$ ), and gelatin content (at $18 \mathrm{~h}$ solidification time and $23^{\circ} \mathrm{C}$ ). The results show that the Young's modulus of gelatin depends on the temperature, solidification time, and gel weight percent. However, these variables do not have strong impact on the Poisson's ratio of the gelatin. At the standard conditions of gelatin which is used in the hydraulic fracturing test in the next Section ( $8 \%$ weight fraction, $18 \mathrm{~h}$ solidifying time and $23{ }^{\circ} \mathrm{C}$ ), the average Possion's ratio measured is 0.497 .

\subsection{Applying Tri-axial Stress Conditions on the Gelatin Block and Placing the Well}

To apply stresses in three dimensions on the gelatin block, the solid gelatin block is coated with a thin layer of oil (PAM 10056510, ConAgra Foods) and then it is placed back into

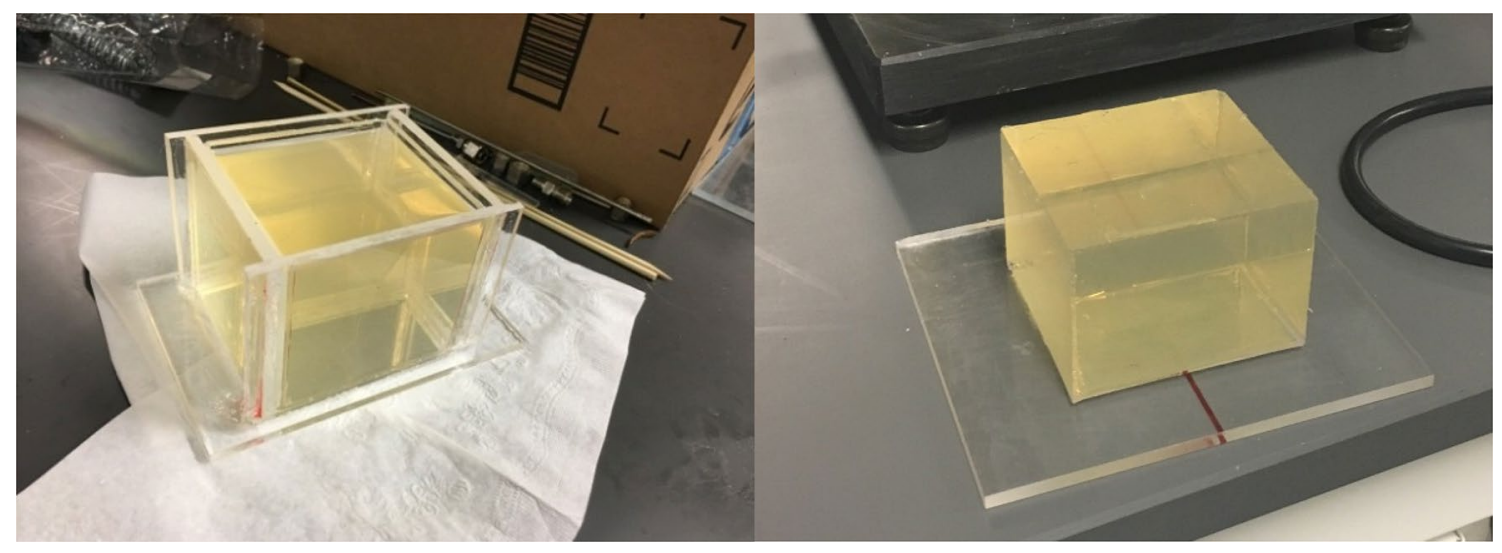

Fig. 1 Gelatin block in container and on flat surface 

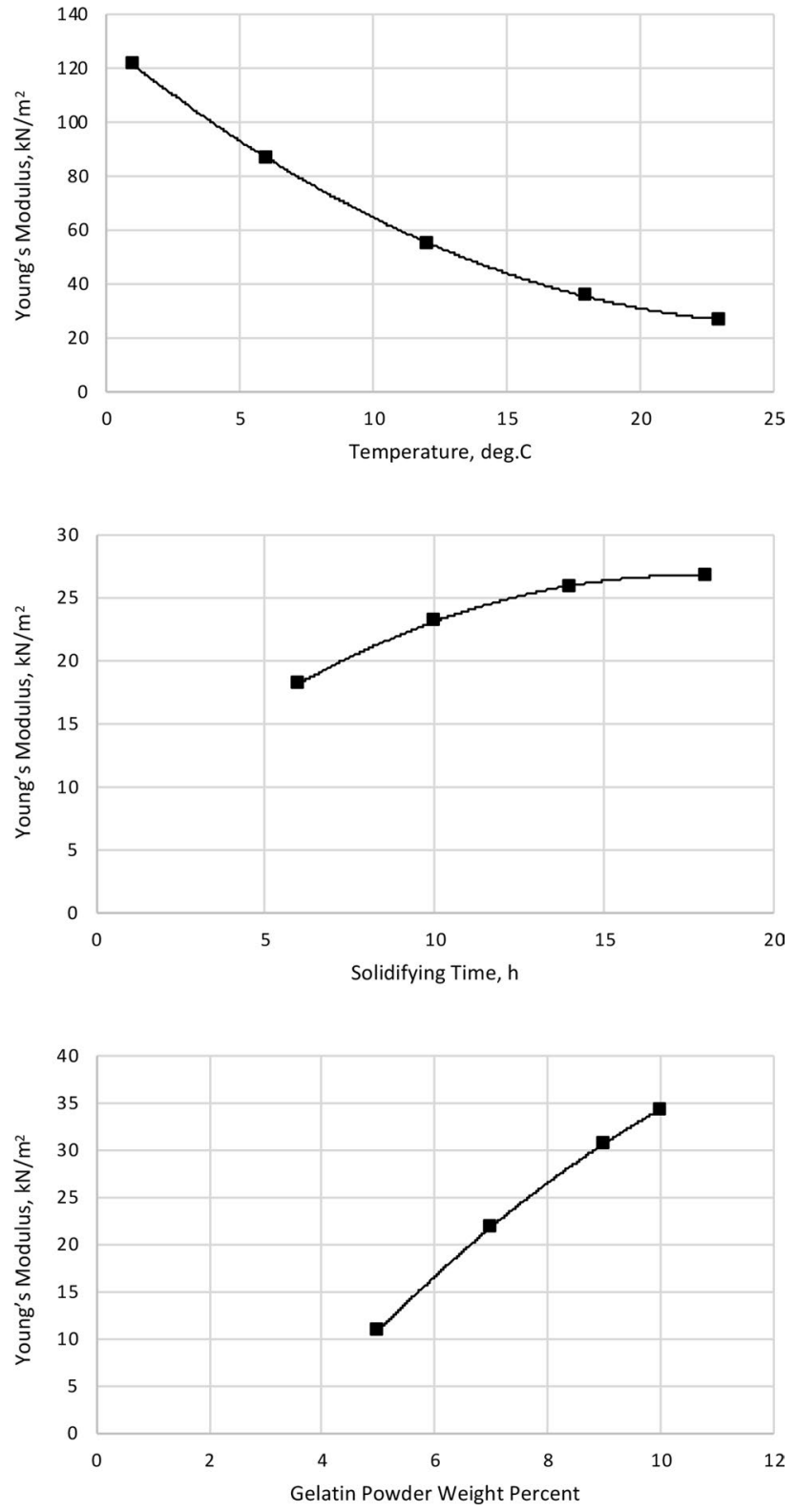

Fig. 2 Young's modulus of gelatin versus temperature (at 8 wt.\% gelatin and $18 \mathrm{~h}$ solidification time), solidification time (at $8 \mathrm{wt} . \%$ gelatin and $23{ }^{\circ} \mathrm{C}$ ), and gelatin content (at $18 \mathrm{~h}$ solidification time and $\left.23{ }^{\circ} \mathrm{C}\right)$

the hydraulic fracturing container. The oil coating makes it easy to insert the gelatin block into the hydraulic fracturing container.

In the experiments conducted here, two stress conditions are simulated. In the first set of conditions, referred to as Case $1, \sigma_{1}=\sigma_{\mathrm{H}}, \sigma_{2}=\sigma_{\mathrm{V}}, \sigma_{3}=\sigma_{\mathrm{h}}$, where $\sigma_{\mathrm{H}}>\sigma_{\mathrm{V}}>\sigma_{\mathrm{h}}$, as shown in Fig. 3a. In this case, the vertical stress is applied on a glass plate that sits at the top of the gelatin thus providing a uniform load on the gelatin block. Stainless steel tubes with a glass sheet directly in contact with the two opposite sides of the gelatin block impose a horizontal load on the block. The other two opposite sides are not loaded. Because the three principle stresses are balanced as the liquid gelatin solidifies, the vertical stress initially at the central point of the gelatin block (which is where the well outlet is positioned) is equal to be the stress caused by the gelatin's mass above that point plus atmosphere pressure, which can be expressed as $P_{\text {atm }}+P_{\mathrm{G}-\text { gelatin }}$. The vertical stress is increased by the total weight on the glass sheet at the top of the gelatin block divided by glass sheet's area, and the stresses in horizontal directions can be calculated using the Generalized Hooke's Law:

$\varepsilon_{x x}=\frac{1}{\mathrm{E}}\left(\sigma_{x x}-\nu \sigma_{y y}-\nu \sigma_{z z}\right)$

$\varepsilon_{y y}=\frac{1}{\mathrm{E}}\left(\sigma_{y y}-\nu \sigma_{x x}-\nu \sigma_{z z}\right)$

where E is Young's modulus and $v$ is Poisson's ratio. After re-arrangement:

$\sigma_{x x}=\frac{E \varepsilon_{x x}+\nu E \varepsilon_{y y}+\left(\nu^{2}+\nu\right) \sigma_{z z}}{1-\nu^{2}}$

$\sigma_{y y}=\frac{E \varepsilon_{y y}+\nu E \varepsilon_{x x}+\left(\nu^{2}+\nu\right) \sigma_{z z}}{1-\nu^{2}}$

By measuring the horizontal strain in $\mathrm{X}$ and $\mathrm{Y}$ directions after treatment, the three principle stresses applied at the center of the gelatin block (bottom hole location) for this case can be calculated. The results are: $\sigma_{\mathrm{V}}=89.9 \mathrm{kPa}, \sigma_{\mathrm{H}}=$ $91.9 \mathrm{kPa}$, and $\sigma_{\mathrm{h}}=87.8 \mathrm{kPa}$.

In the second set of conditions, referred to as Case 2, $\sigma_{1}=\sigma_{2}=\sigma_{\text {horizontal }}, \sigma_{3}=\sigma_{\text {vertical }}$ where $\sigma_{\mathrm{H}}=\sigma_{\mathrm{h}}>\sigma_{\mathrm{V}}$, as shown in Fig. 3b. In this case, stainless steel tubes with glass sheets are used to load the block in both side directions and no load is placed on the block in the vertical direction. Using same method derived in Case 1, the three principle stress at the bottom hole location can be calculated and the results are: $\sigma_{\mathrm{V}}=88.7 \mathrm{kPa}$, and $\sigma_{\mathrm{H}}=\sigma_{\mathrm{h}}=90.7 \mathrm{kPa}$.

\subsection{Placing the Well Within the Block}

To place the well into the gelatin block, a heated metal tube was inserted into the gelatin block to make a center hole (sized slightly larger than the well) and then it is pulled out. This established the well hole within the block. Next, the well, wrapped in a cloth tape and then smeared with epoxy glue is placed within the block. The glue simulates the cementing process as is done with real wells. Next, a thin tube with outer diameter slightly smaller than the well's inner diameter is placed inside the well. By insertion, the thin tube will block the outer well to prevent liquid 


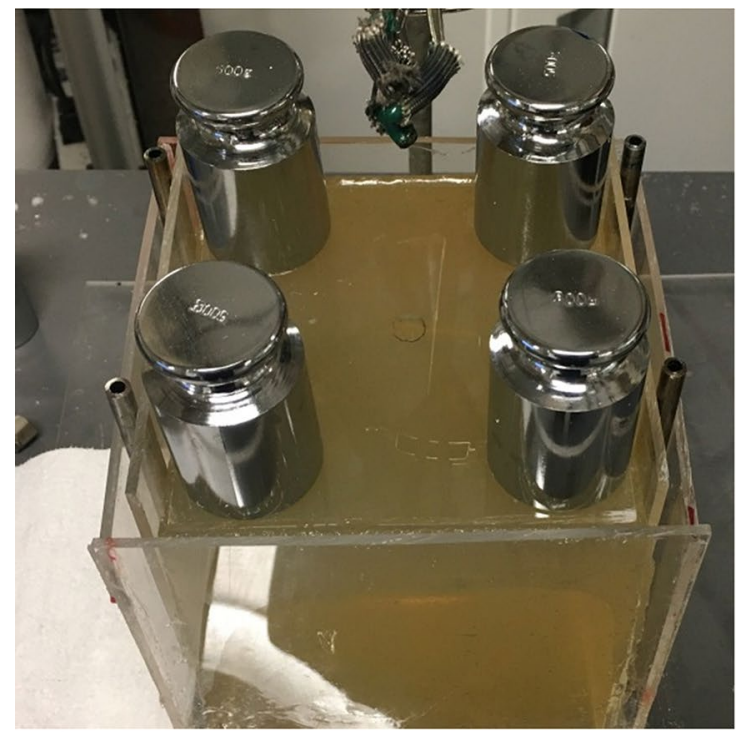

(a)

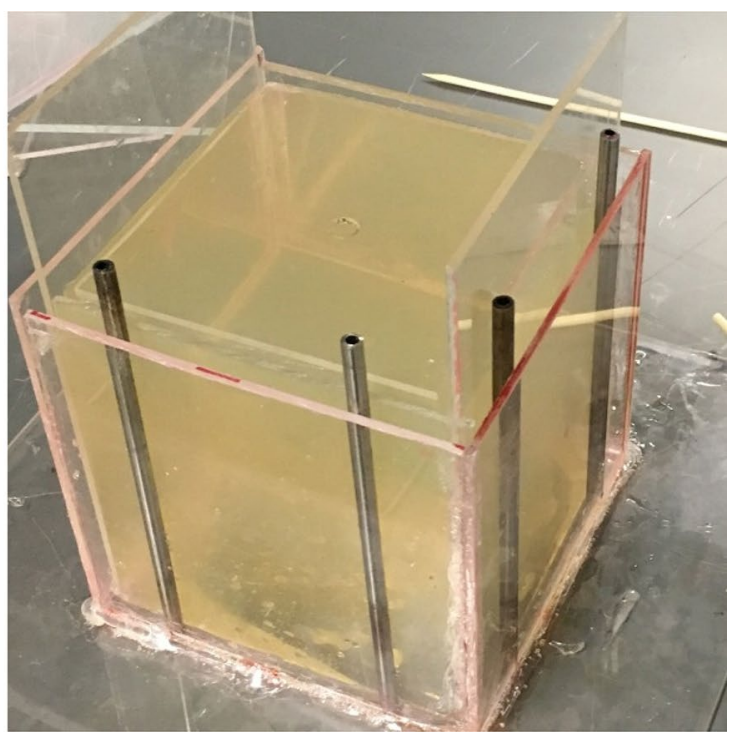

(b)

Fig. 3 Physical experiment conditions imposed on gelatin block to obtain a vertical fracture and $\mathbf{b}$ horizontal fracture

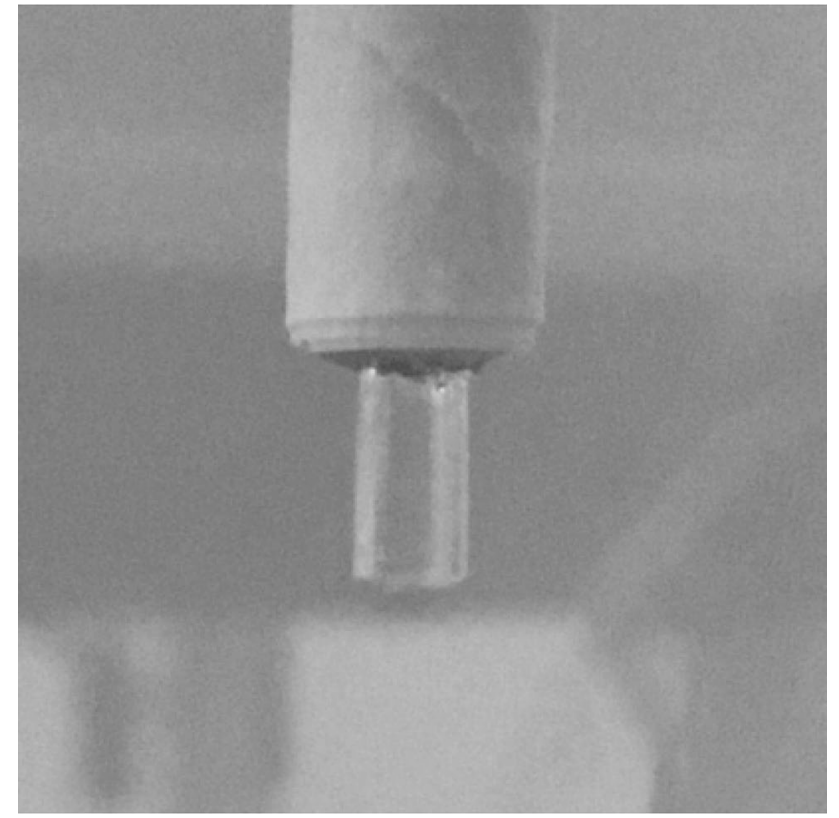

Fig. 4 Cylindrical space at base of the well within the gelatin block. The well is a $1 \frac{1}{4}$ inch stainless steel tube

gel solution entry. The thin tube is placed at a depth just $0.3-0.5 \mathrm{~cm}$ below the wellbore. The apparatus is then left for another $18 \mathrm{~h}$ to solidify the liquefied gelatin solution that might exist near the well (caused from the hot tube inserted initially into the gelatin block). Before conducting the hydraulic fracturing experiment, the inner tube is removed and a small cylindrical space below the wellbore is left to simulate a section of open hole, as shown in Fig. 4.

\subsection{Hydraulic Fracturing Fluids}

The hydraulic fracturing fluid for both vertical and horizontal fracture experiments is red ink (RED 44645, Higgins) with viscosity equal to $2.62 \mathrm{cP}$. Initially, the well is filled with the hydraulic fracturing fluid to eliminate air bubbles in the well. When hydraulic fracturing test proceeds, the fluid is injected into the well at a prescribed flow rate $(0.1 \mathrm{ml} / \mathrm{min})$. Three cameras are placed around the gelatin cube to record the evolution of the hydraulic fractures within the gelatin. The size of the fractures are measured from recorded images of the hydraulic fractures versus time.

\section{Hydraulic Fracturing Theory}

Sneddon and Elliot (1946) derived the stress field around an oval fracture under static pressure. They found that for a radial fracture with flat shape, the fracture width can be expressed as

$W_{(\mathrm{r})}=\frac{8 P_{\mathrm{net}} R\left(1-v^{2}\right)}{\pi E} \sqrt{1-\left(\frac{r}{R}\right)^{2}}$,

where $P_{\text {net }}$ is the pressure inside the fracture minus the minimum principle stress. At the central point of the fracture, $r=0$, Eq. (5) can be simplified to

$W_{\mathrm{w}}=\frac{8 P_{\mathrm{net}} R\left(1-v^{2}\right)}{\pi E}$ 
From ellipsoid volume's equation (with equal horizontal axial length):

$V=\frac{4 \pi \mathrm{R}^{2}\left(\frac{W_{\mathrm{w}}}{2}\right)}{3}$

where $V$ is the fracture's volume. Then by substituting Eq. (6) into Eq. (7), the fracture radius is given by

$R=\sqrt[3]{\frac{3 V E}{16\left(1-v^{2}\right) P_{\text {net }}}}$

If the injection rate $q_{\mathrm{i}}$ is constant and fluid leak off can be ignored, then the volume of the fracture can be calculated as

$V=q_{\mathrm{i}} t$.

In addition, if the injection rate is very small and the pressure drop caused by fluid flow can be ignored, $P_{\text {net }}$ can be calculated as

$P_{\text {net }}=P_{\text {injection }}-\sigma_{3}$.

Equation (8) is the theoretical basis of the 2D PKN and KGD models (Geertsma and Klerk 1969; Economides and Nolte 1989). However, here, a modification of the injection volume needs to be made to the original equations. As shown in Fig. 4, there is a small cylindrical space at base of the well to simulate an open hole. In addition, near the wellbore, there may be some small branches cracking at the beginning of injection due to the gelatin heterogeneity close to the well. Therefore, the main fracture volume will be a little bit smaller than the injected liquid volume. If we use $V_{0}$ to express this wasted volume which does not contribute to the main hydraulic fracture, then the result is

$R=\sqrt[3]{\frac{3\left(q_{\mathrm{i}} t-V_{0}\right) E}{16\left(1-v^{2}\right)\left(P_{\text {injection }}-\sigma_{3}\right)}}$

and

$W_{(\mathrm{r})}=\frac{8\left(P_{\text {injection }}-\sigma_{3}\right) R\left(1-\nu^{2}\right)}{\pi E} \sqrt{1-\left(\frac{r}{R}\right)^{2}}$

\section{Results and Discussion}

\subsection{Vertical Fracture Propagation}

In Case 1 (injection rate equal to $0.1 \mathrm{ml} / \mathrm{min}$ ), the hydraulic fracture propagates into the gelatin with the consequent creation of a vertical fracture, as displayed in Fig. 5. The results show that the fracture is not symmetric around the injection wellbore. This is due to imperfect vertical well placement and the internal heterogeneity of the gelatin especially in the neighborhood of the injection well. As described above, the steel tube is heated to place it within the gelatin and as a consequence, there will be small irregular re-melt zone along the well which re-solidifies around the tube which in turn causes a stress distribution anomaly near the wellbore. At the beginning, when the liquid is injected into the gelatin, it penetrates the heterogeneous near-well region. Thereafter, the hydraulic fracture evolves into its full form within the gelatin.

As shown in Fig. 5, the fracture's shape is not perfectly circular, but we can regard the fracture's shape as a 3D curved fan-shaped ellipsoid. Although the radius of the fracture in different directions are different, we can still get an average $R$ value to compare with the one in the theory. Steps to get the experimental observed average fracture radius $R$ and an example figure is described as follows.

As shown in Fig. 6, for a curved fan-shaped ellipsoid fracture, the first step is to determine the pixel point coordinate $\left(x_{0}, y_{0}\right)$ of the injection central point. The second step is to get the angle of our incomplete fan-shaped fracture. As shown in Fig. 6, the fracture is not a complete $360^{\circ}$ ellipsoid, so the volume formula of the fracture in theory also needs to be modified, because the averaged radius $R$ is obtained from a complete ellipsoid's volume formula. For a complete ellipsoid with average horizontal radius $R$ and vertical half axial length $\frac{W_{\mathrm{w}}}{2}$ :

$V=\frac{4 \pi R^{-2}\left(\frac{W_{\mathrm{w}}}{2}\right)}{3}$

The volume of an incomplete fan-shaped ellipsoid with angle of $\theta$ can be expressed as

$V=\frac{4 \pi R^{-2}\left(\frac{W_{\mathrm{w}}}{2}\right)}{3} \frac{\theta}{2 \pi}$

Then, the fracture radius derived above can be modified to

$\bar{R}=\sqrt[3]{\frac{3\left(q_{\mathrm{i}} t-V_{0}\right) E}{16\left(1-\nu^{2}\right)\left(P_{\text {injection }}-\sigma_{3}\right)} \frac{2 \pi}{\theta}}$

A protractor can be used to get the value of fracture's fan-shape angle $\theta$. As shown in Fig. 6b, in this experiment, the total angle of the vertical fracture, $\theta$, is equal to about $300^{\circ}\left(\frac{5 \pi}{3}\right)$.

In the third step, the radial extent of the fracture along rays radiating (at each $30^{\circ}$ ) from the central point is determined from the image. From these lengths, we cannot simply use the geometrical mean or arithmetic mean to get the average radius, $R$. We need to derive the formulas of 

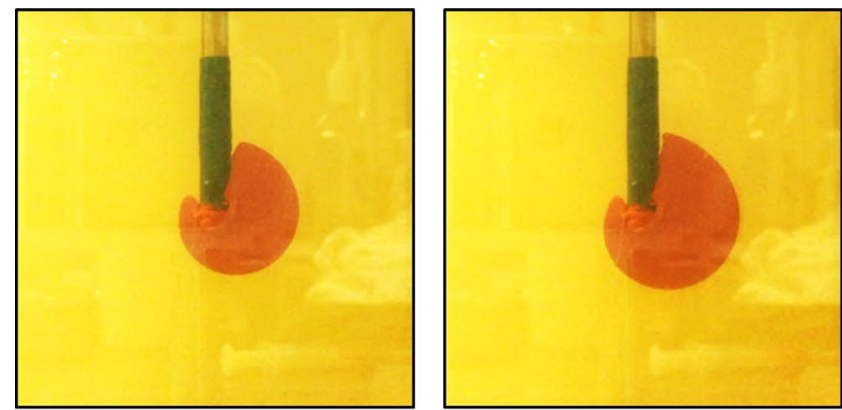

8 mins

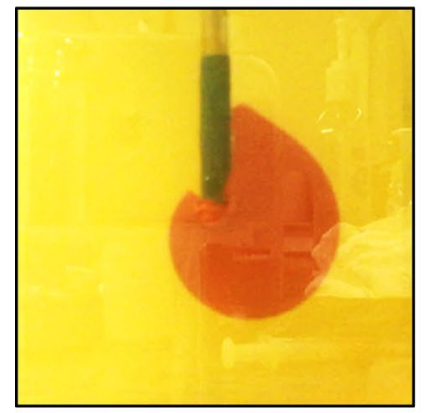

12 mins

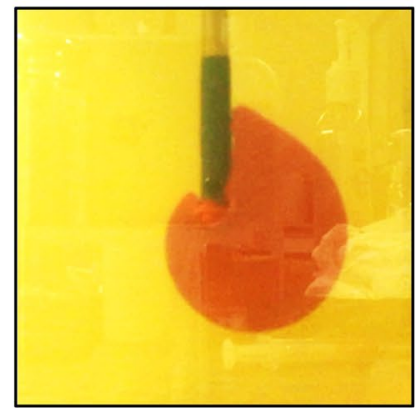

$24 \min$
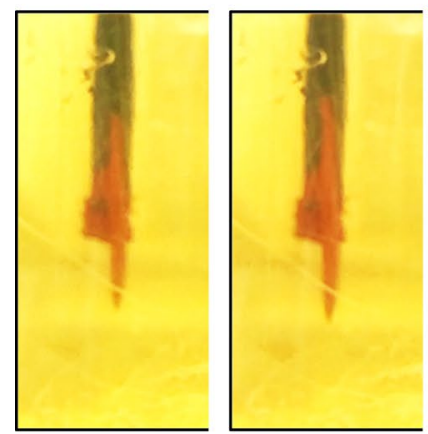

8 min
$28 \min$

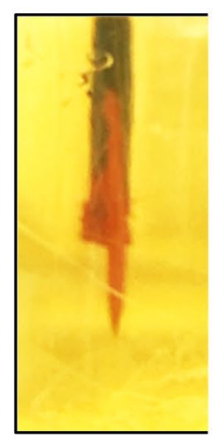

$16 \min$

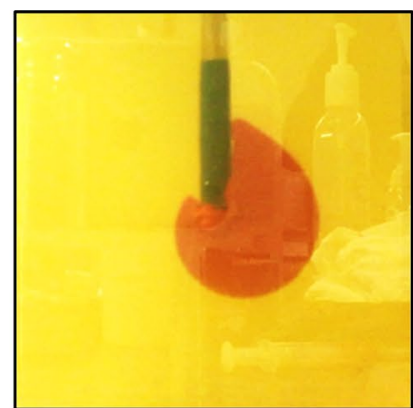

16 mins

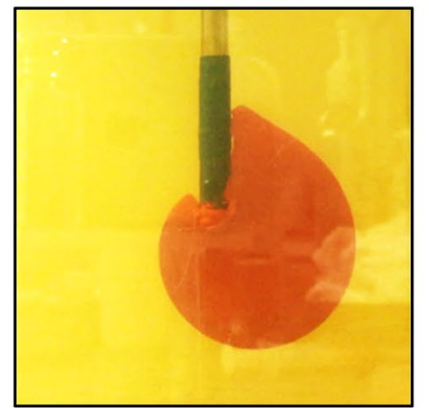

$32 \mathrm{~min}$

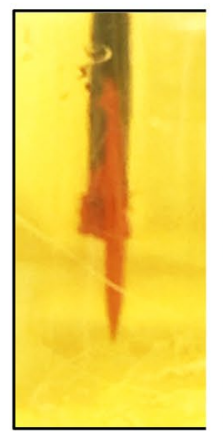

$20 \mathrm{~min}$

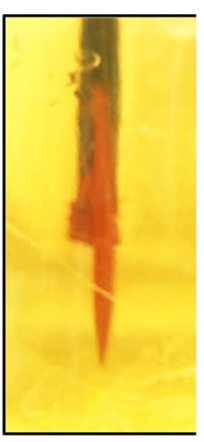

$24 \min$

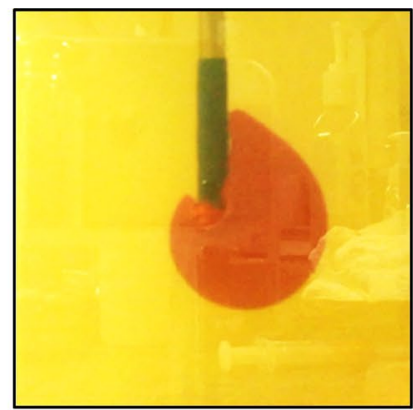

20 mins

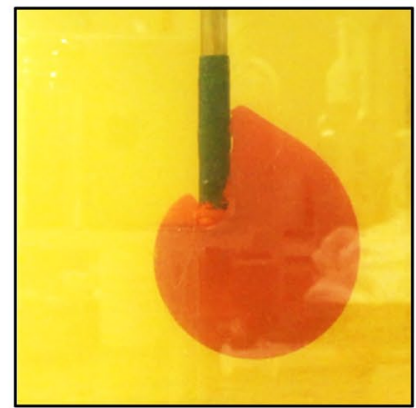

$36 \min$
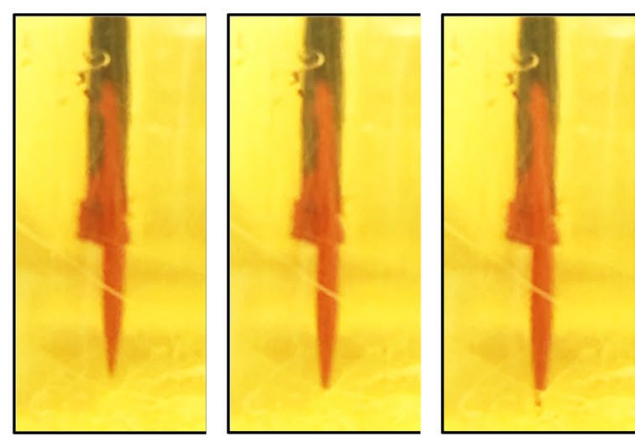

$32 \mathrm{~min} \quad 36 \mathrm{~min}$

Fig. 5 Case 1: Front view and right view of an vertical fracture evolution with time at injection rate equal to $0.1 \mathrm{ml} / \mathrm{min}(8 \mathrm{wt} \%$ gelatin in $15 \mathrm{~cm}$ by $15 \mathrm{~cm}$ by $15 \mathrm{~cm}$ cube, $18 \mathrm{~h}$ solidification time, conducted at $23^{\circ} \mathrm{C}$ )

$\bar{R}$ using the volume of a curved-edge fan-shaped ellipsoid expressed by Eq. (14).

The volume can also be estimated by summing the volume associated with each ray of the ellipse:

$V_{\text {total }}=\sum_{i=1}^{n} \frac{4 \pi R_{\mathrm{i}}^{2}\left(\frac{W_{\mathrm{w}}}{2}\right)}{3} \frac{\left(\frac{\theta}{n}\right)}{2 \pi}$

where $n$ is the number of rays of the ellipse. Equating Eqs. (14 and 17) gives

$$
\frac{4 \pi R^{-2}\left(\frac{W_{\mathrm{w}}}{2}\right)}{3} \frac{\theta}{2 \pi}=\sum_{i=1}^{n} \frac{4 \pi R_{i}^{2}\left(\frac{W_{\mathrm{w}}}{2}\right)}{3} \frac{\left(\frac{\theta}{n}\right)}{2 \pi}
$$

which then implies that the average fracture radius is

$$
\bar{R}=\sqrt{\frac{\sum_{i=1}^{n} R_{\mathrm{i}}^{2}}{n}}
$$




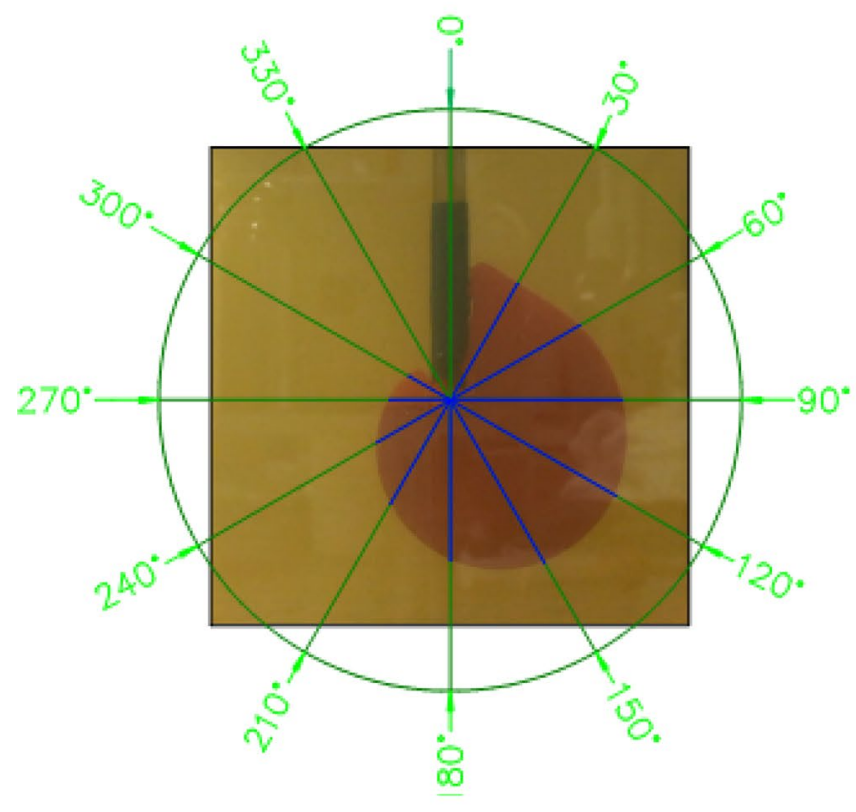

(a)

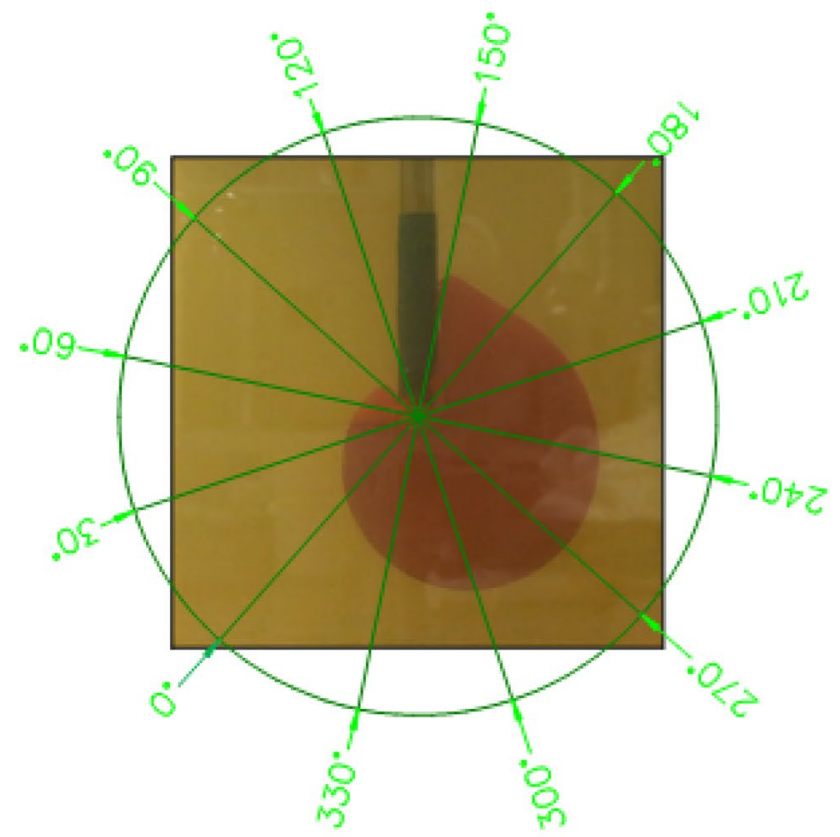

(b)

Fig. 6 Example of a image processing method to get $\bar{R}$ for an vertical fracture at injection time of 36 min and $\mathbf{b}$ where angle of missing part of fracture is determined

The fourth step is to correct any error caused by the vertical inclination of the fracture. As shown in fracture's right view images in Fig. 5, the fracture may not be perfectly vertical due to gel heterogeneity. The fracture recorded by our camera may need a correction if the inclination angle is large. In the vertical fracture experiment conducted here, the fracture can be roughly seen as vertical and thus, no correction is required.

At $23{ }^{\circ} \mathrm{C}$, the Young's modulus and Poisson's ratio of the gelatin are $26,733 \mathrm{~N} / \mathrm{m}^{2}$ and 0.497 , respectively. Because the fracture width is too difficult to measure precisely in current procedure, only fracture radius is discussed in this section. In this test, the build-up-volume prior to fracturing, $V_{0}$, in Eq. (15) is estimated to be $0.05 \mathrm{ml}$. The injection pressure, experimental average fracture radius measured from images, and the theoretical fracture radius calculated by the modified oval fracture model are recorded at each injection time. Table $1 \mathrm{com}-$ pares the experimental and theoretical values. The results reveal that the experimental and theoretical results compare excellently to each other. The percentage difference between the results over the $36 \mathrm{~min}$ of injection remains below $10 \%$. The results reveal that the theory tends to overpredict the fracture radius at the early stage but underpredict the fracture radius after it grows larger. In addition, the larger the fracture grows, the general trend is that the differences between experimental values and theoretical values become larger. This likely because the deformation
Table 1 Comparison in vertical fracture experiments with the radial fracture theory

\begin{tabular}{lllll}
\hline $\begin{array}{l}\text { Injection time } \\
(\mathrm{min})\end{array}$ & $\begin{array}{l}\text { Injection pressure } \\
(\mathrm{kPa})\end{array}$ & $\begin{array}{l}\text { Experimental average } \\
\text { fracture radius }(\mathrm{cm})\end{array}$ & $\begin{array}{l}\text { Theoretical fracture } \\
\text { radius }(\mathrm{cm})\end{array}$ & $\begin{array}{l}\text { Absolute } \\
\text { percentage differ- } \\
\text { ence }(\%)\end{array}$ \\
\hline 8 & 90 & 1.3792 & 1.3965 & -1.25 \\
12 & 90 & 1.5977 & 1.6103 & -0.79 \\
16 & 90 & 1.7419 & 1.7788 & -2.10 \\
20 & 90 & 1.8954 & 1.9202 & -1.32 \\
24 & 90 & 2.0637 & 2.0434 & +0.99 \\
28 & 90 & 2.2077 & 2.1534 & +2.52 \\
32 & 90 & 2.3870 & 2.2531 & +5.94 \\
36 & 90 & 2.5109 & 2.3447 & +7.09 \\
\hline
\end{tabular}




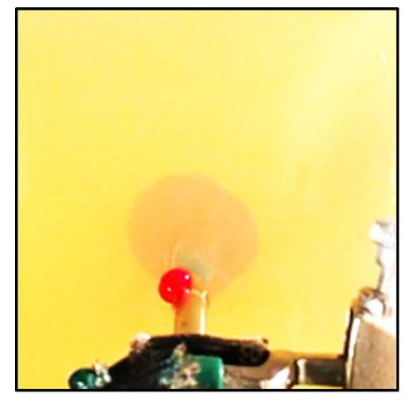

$10 \mathrm{~min}$

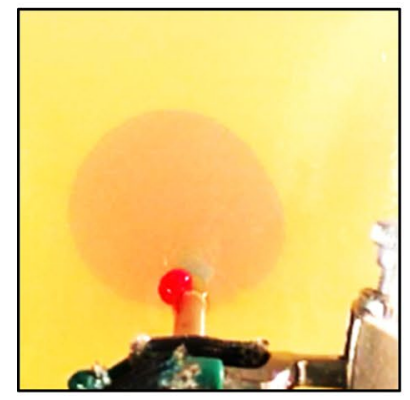

34 min

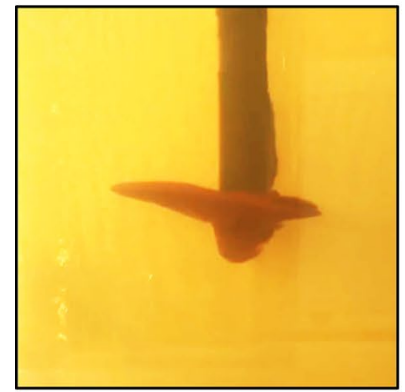

$10 \mathrm{~min}$

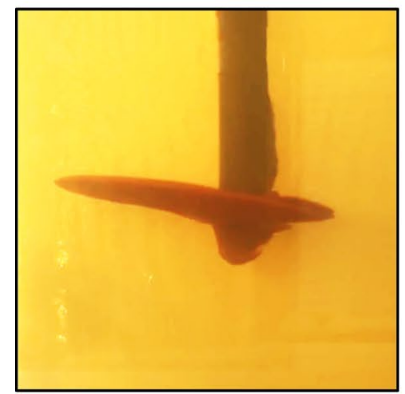

$34 \mathrm{~min}$

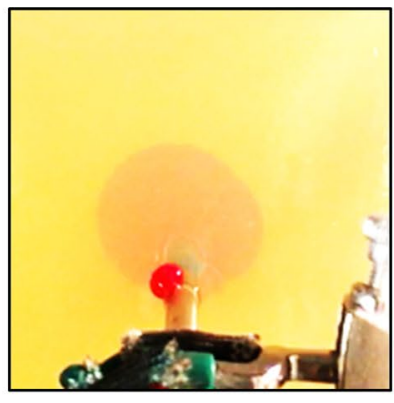

18 min

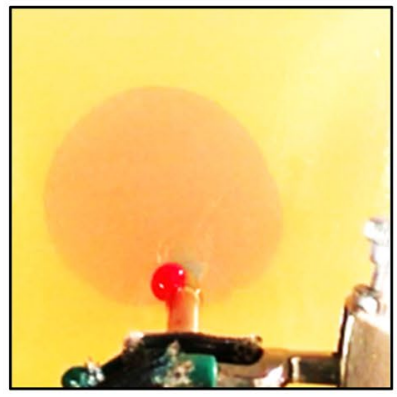

42 min

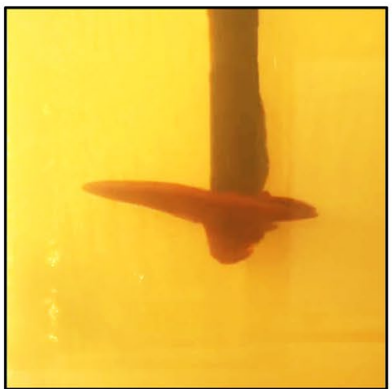

18 min

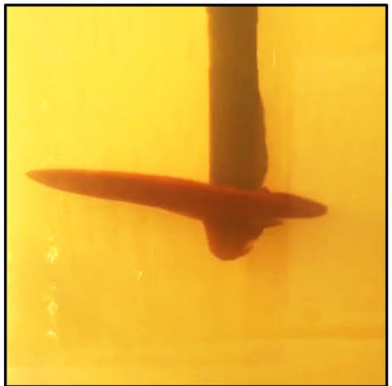

42 min

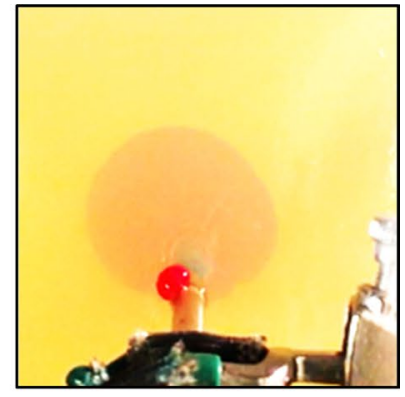

26 min

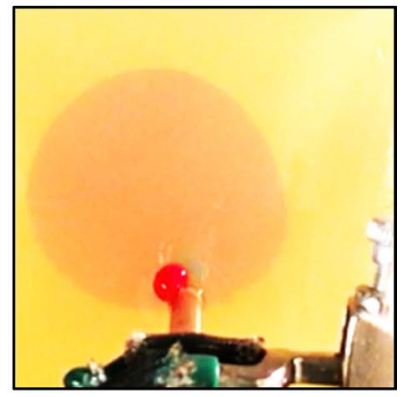

50 min

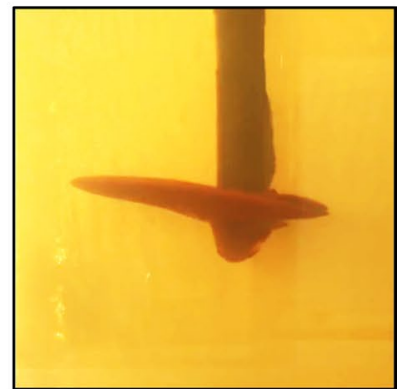

$26 \min$

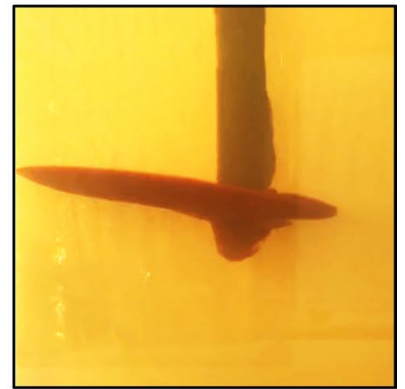

$50 \mathrm{~min}$

Fig. 7 Case 2: horizontal fracture evolution with time at injection rate equal to $0.1 \mathrm{ml} / \mathrm{min}(8 \mathrm{wt} . \%$ gelatin in $15 \mathrm{~cm}$ by $15 \mathrm{~cm}$ by $15 \mathrm{~cm}$ cube, $18 \mathrm{~h}$ solidification time, conducted at $23{ }^{\circ} \mathrm{C}$ ) 
is exceeding the linear elastic limit. Another explanation for the deviation is that the underlying theory, expressed in Eq. (5), is based on an infinite two-dimensional elastic medium. In the experiment, there are boundaries that at some point, as the fracture grows large in the domain start to influence the growth of the fracture.

\subsection{Horizontal Fracture Propagation}

In Case 2 (injection rate equal to $0.1 \mathrm{ml} / \mathrm{min}$ ), with results displayed in Fig. 7, a near horizontal fracture propagates into the gelatin. Images of the fracture from top and front views are recorded. For the top view images, the camera is set $50 \mathrm{~cm}$ up and $10 \mathrm{~cm}$ left to the wellbore, and the image is shot from an angle of $11.3^{\circ}$ to the vertical direction. Steps to determine the horizontal fracture radius in this case are the same as those in vertical one except that the shape is changed. Therefore, the angle $\theta$ in Eq. (15) needs to be modified to $2 \pi$. In addition, a correction needs to be made due to the camera's oblique shooting angle. From the front view images in Fig. 7, we can see that the fracture is not perfectly horizontal. An inclination angle about $7^{\circ}$ to the horizontal direction is measured. After calculation, the error caused by this inclination is found to be lower than $1 \%$, and thus it can be ignored.

The Young's modulus and Poisson's ratio for Case 2 is the same as that of Case 1 and the initial volume of the injected fluid required to start fracturing, $V_{0}$, is estimated to be $0.05 \mathrm{ml}$. A comparison of the experimental and theoretical results are listed in Table 2. The results reveal that the experimental and theoretical results are well matched at different injection times throughout the experiment, but that the theory overestimates the size when the fracture is small and underestimates it when the fracture is large. At later times, where the deformation is beyond linear elastic response and thus the theory underestimates the fracture size. Similar to the vertical fracture, another reason for the deviation between the theory and experimental results is that that the model describes the case of an infinite two-dimensional elastic medium which is strictly not the case for the bounded gel block.

\subsection{Scaling Theory for Hydraulic Fracturing}

From the analysis above, a simple scaling theory can be constructed as follows:

$R_{\mathrm{M}}\left[\frac{\left(1-v_{\mathrm{M}}^{2}\right) P_{\mathrm{net}, \mathrm{M}}}{q_{\mathrm{i}_{\mathrm{M}}} t_{\mathrm{M}} E_{\mathrm{M}}}\right]^{1 / 3}=R_{F}\left[\frac{\left(1-v_{\mathrm{F}}^{2}\right) P_{\mathrm{net}, \mathrm{F}}}{q_{\mathrm{i}_{\mathrm{F}}} t_{\mathrm{F}} E_{\mathrm{F}}}\right]^{1 / 3}$,

where the subscripts $\mathrm{M}$ and $\mathrm{F}$ represent the physical model and field scales, respectively. Equation (20) provides an estimate of the size of the fracture as would be expected in the field given data from the physical model experiment in the laboratory. In the first example, an examination of the 12 stage hydraulic fracturing operation at the Hoadley Field near Rimbey, Alberta, Canada operated by ConocoPhillips Canada. The two wells were monitored with a vertical sensor array in a nearby vertical well. The fractured formation is the Glauconite Formation with thickness $\sim 43 \mathrm{~m}$. The depth of the wells is equal to about $1900 \mathrm{~m}$ with lateral intervals equal to $2000 \mathrm{~m}$ (Maulianda 2016). From Maulianda's analysis, of the microseismic data, displayed in Fig. 8, the average horizontal extent of the fractures was equal to about $166 \mathrm{~m}$ and the average vertical height of the fractures was equal to about $62 \mathrm{~m}$. This yields an areal equivalent radius equal to about $57 \mathrm{~m}$ (approximated from equivalent radius of circle with the same area). The results from the scaling theory, Eq. (20), is plotted in Fig. 9 (Hoadley field data listed in caption of Fig. 9) which illustrates that the theory provides a reasonable estimate of the extent of the fracture in the field. The difference of the values between the theory and the field values is due to the thickness of the reservoir as well as the approximate and constant values used in the calculation. A fracture that propagates within the reservoir will be bounded by the reservoir thickness and it is expected that the fracture would extend further from the injection well as a result.
Table 2 Comparison in horizontal fracture experiments with radial fracture theory

\begin{tabular}{lllll}
\hline $\begin{array}{l}\text { Injection time } \\
(\mathrm{min})\end{array}$ & $\begin{array}{l}\text { Injection pressure } \\
(\mathrm{kPa})\end{array}$ & $\begin{array}{l}\text { Experimental average frac- } \\
\text { ture radius }(\mathrm{cm})\end{array}$ & $\begin{array}{l}\text { Theoretical fracture } \\
\text { radius }(\mathrm{cm})\end{array}$ & $\begin{array}{l}\text { Percentage } \\
\text { difference } \\
(\%)\end{array}$ \\
\hline 10 & 91 & 1.3402 & 1.4009 & -4.3 \\
18 & 91 & 1.6784 & 1.7173 & -2.3 \\
26 & 91 & 1.9334 & 1.9470 & -0.7 \\
34 & 91 & 2.1773 & 2.1324 & +2.1 \\
42 & 91 & 2.4001 & 2.2901 & +4.8 \\
50 & 91 & 2.6469 & 2.4287 & +8.9 \\
\hline
\end{tabular}



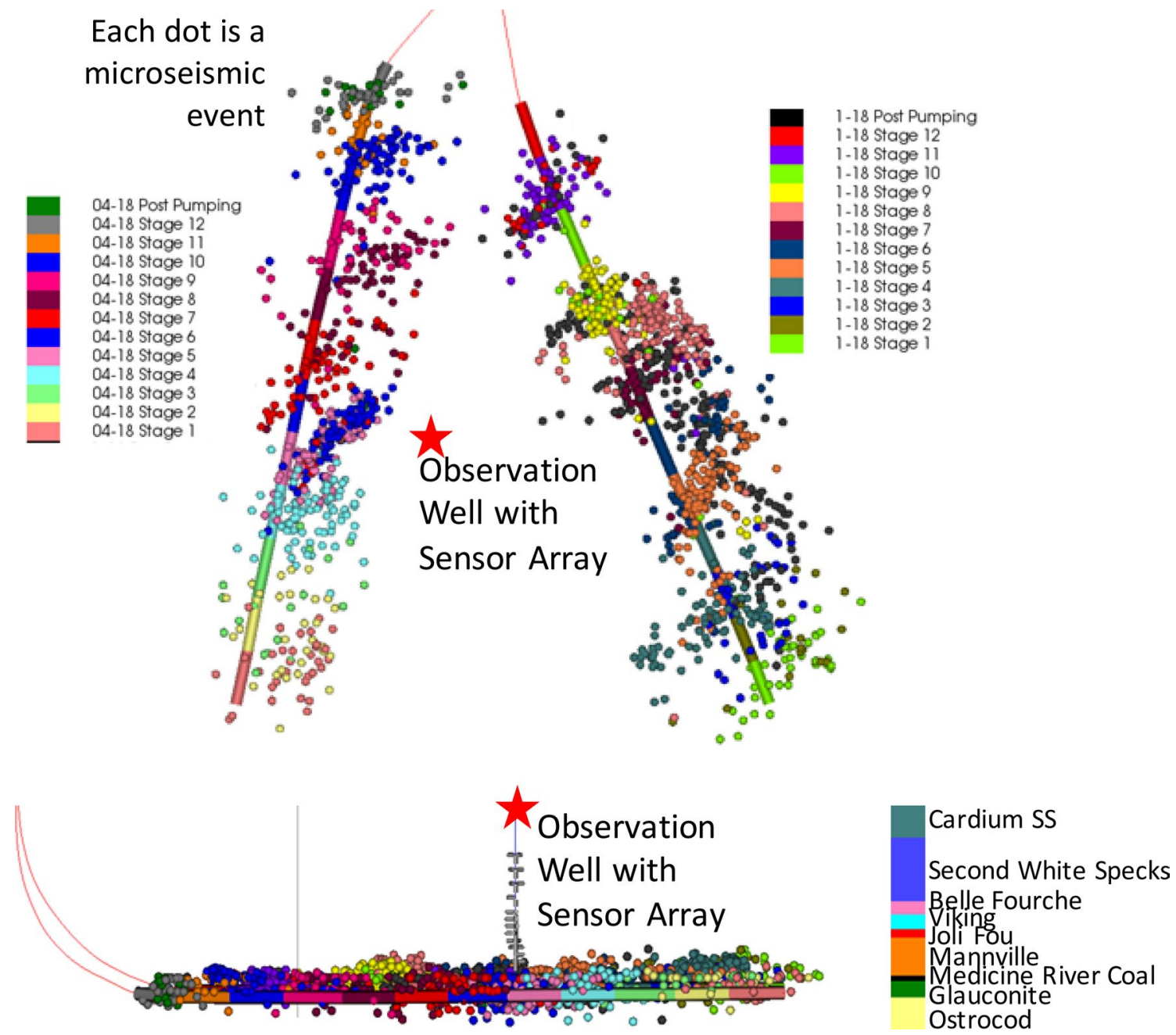

Fig. 8 Summary of the treatment of the two wellbores, observed wellbore, producing wellbore and observed microseismic events during 12 stages of hydraulic fracture (modified from Maulianda 2016)

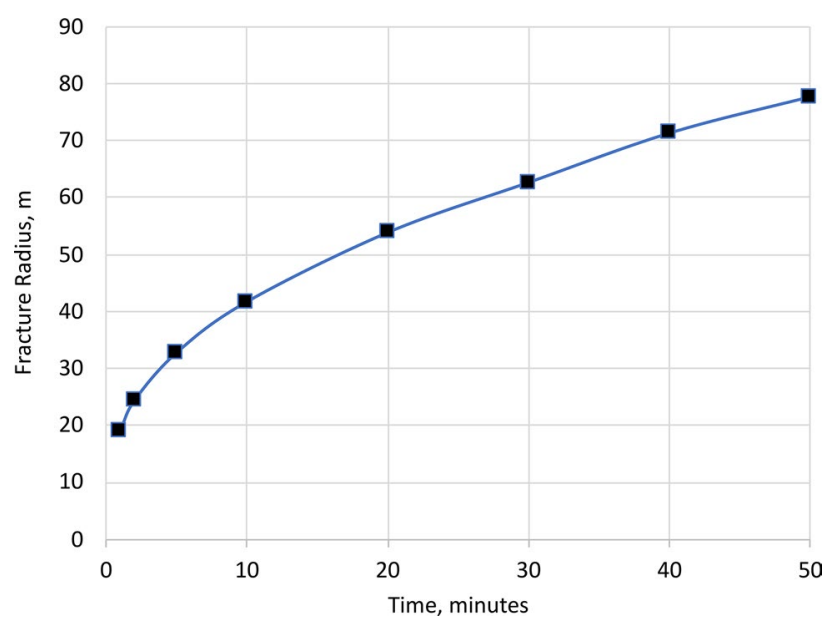

Fig. 9 Fracture size predicted from scaling theory for Hoadley Field, Alberta, Canada (Hoadley Formation properties: $E=4.5 \times 10^{10} \mathrm{~Pa}$, $\nu=0.23$, fluid density $=1000 \mathrm{~kg} / \mathrm{m}^{3}$, injection pressure $=50 \mathrm{MPa}$, injection flow rate $=7200$ tonnes/day, reservoir initial pressure $=19 \mathrm{MPa}$, fracture job durations averaged about $40 \mathrm{~min}$ )

\section{Conclusions}

Using gelatin as a material to simulate hydraulic fracturing in the laboratory is feasible. Under small deformations, it exhibits linear elastic behaviour which can simulate most elastic rocks. In addition, the property data show that the mechanical properties of gelatin is affected by temperature, cooling time, and polymer concentration and thus, it is easy to adjust the mechanical properties, such as Young's modulus, of the gelatin to simulate different formation conditions. The vertical and horizontal fracturing tests reveal relatively close matches with the modified radial fracture model. However, the difference between experimental and theoretical results tends to become larger as the fracture grow. The scaling theory reveals that the gelatin fracturing experiments can be applied for making predictions in real field. For vertical 
fractures evolving beyond the formation's thickness limitations, a more accurate correction is needed.

Acknowledgements The authors acknowledge support from the Natural Science and Engineering Research Council (NSERC) of Canada and the University of Calgary Canada First Research Excellence Fund (CFREF), the Global Research Initiative in Sustainable Low Carbon Unconventional Resources

\section{Compliance with Ethical Standards}

Conflict of Interest The authors declare no conflict of interest with respect to the research and this manuscript.

Open Access This article is licensed under a Creative Commons Attribution 4.0 International License, which permits use, sharing, adaptation, distribution and reproduction in any medium or format, as long as you give appropriate credit to the original author(s) and the source, provide a link to the Creative Commons licence, and indicate if changes were made. The images or other third party material in this article are included in the article's Creative Commons licence, unless indicated otherwise in a credit line to the material. If material is not included in the article's Creative Commons licence and your intended use is not permitted by statutory regulation or exceeds the permitted use, you will need to obtain permission directly from the copyright holder. To view a copy of this licence, visit http://creativecommons.org/licenses/by/4.0/.

\section{References}

Arthur J D, Bohm B K, Coughlin B J, et al (2009) Evaluating the environmental implications of hydraulic fracturing in shale gas reservoirs. In: Paper SPE-121038-MS presented at the SPE Americas E\&P environmental and safety conference

Blanton TL (1982) An experimental study of interaction between hydraulically induced and pre-existing fractures. In: Paper SPE10847-MS presented at the SPE unconventional gas recovery symposium

Cipolla CL, Lolon EP, Erdle JC et al (2010) Reservoir modeling in shale-gas reservoirs. SPE Reserv Eval Eng 13(4):638-653

Economides MJ, Nolte KG (1989) Reservoir stimulation. Prentice Hall, Englewood Cliffs

Geertsma J, De Klerk F (1969) A rapid method of predicting width and extent of hydraulically induced fractures. J Petrol Technol 21(12):1571-1581

Gregory KB, Vidic RD, Dzombak DA (2011) Water management challenges associated with the production of shale gas by hydraulic fracturing. Elements 7(3):181-186
Jaworski GW, Duncan JM, Seed HB (1981) Laboratory study of hydraulic fracturing. J Geotech Eng Div Am Soc Civ Eng 107:GT6

Kang HW, Tabata Y, Ikada Y (1999) Fabrication of porous gelatin scaffolds for tissue engineering. Biomaterials 20(14):1339-1344

Kwon J, Subhash G (2010) Compressive strain rate sensitivity of ballistic gelatin. J Biomech 43(3):420-425

Lee KY, Mooney DJ (2001) Hydrogels for tissue engineering. Chem Rev 101(7):1869-1880

Lockner D (1993) The role of acoustic emission in the study of rock fracture. Int J Rock Mech Min Sci 30(7):883-899

Matsunaga I, Kobayashi H, Sasaki S et al (1993) Studying hydraulic fracturing mechanism by laboratory experiments with acoustic emission monitoring. Int J Rock Mech Min Sci 30(7):909-912

Maulianda BT (2016) On hydraulic fracturing of tight gas reservoir rock. Ph.D. Thesis, University of Calgary

Olson JE (2008) Multi-fracture propagation modeling: Applications to hydraulic fracturing in shales and tight gas sands. In: Paper ARMA08-327 presented at the American Rock Mechanics Association 42nd US Rock Mechanics Symposium

Potluri NK, Zhu D, Hill AD (2005) The effect of natural fractures on hydraulic fracture propagation. In: Paper SPE-94568-MS presented at the Society of Petroleum Engineers European Formation Damage Conference

Rahm D (2011) Regulating hydraulic fracturing in shale gas plays: the case of Texas. Energy Policy 39(5):2974-2981

Rodgerson JL (2000) Impact of natural fractures in hydraulic fracturing of tight gas sands. In: Paper SPE-59540-MS presented at the SPE Permian basin oil and gas recovery conference

Rutqvist J, Rinaldi AP, Cappa F et al (2013) Modeling of fault reactivation and induced seismicity during hydraulic fracturing of shalegas reservoirs. J Petrol Sci Eng 107:31-44

Salisbury CP, Cronin DS (2009) Mechanical properties of ballistic gelatin at high deformation rates. Exp Mech 49(6):829

Sneddon IN, Elliott HA (1946) The opening of a griffith crack under internal pressure. Q Appl Math 4(3):262-267

Teufel LW, Clark JA (1981) Hydraulic-fracture propagation in layered rock: experimental studies of fracture containment. Sandia National Labs, Albuquerque

Warpinski NR (1990) Dual leakoff behavior in hydraulic fracturing of tight, lenticular gas sands. SPE Prod Eng 5(3):243-252

Warpinski NR (1991) Hydraulic fracturing in tight, fissured media. J Petrol Technol 43(02):146-209

Zoback MD, Rummel F, Jung R et al (1977) Laboratory hydraulic fracturing experiments in intact and pre-fractured rock. Int J Rock Mech Min Sci 14(2):49-58

Publisher's Note Springer Nature remains neutral with regard to jurisdictional claims in published maps and institutional affiliations. 